\title{
Editorial
}

\section{How to maintain a brand properly}

\section{THE BRAND AND ITS CONTENT}

In my book 'Voyage Symbolique dans la Marque'1 I illustrated, using numerous examples, the hidden content that lies in the majority of brands and through this demonstrated the importance of the mythology attached to a brand in order to uncover its timeless roots. I would only repeat again that it is not unimportant to use sign-symbols in such a way that the symbolic content becomes much more important than the simple expression of a product or service. Whether this sign is a number, a colour or an ideogram, many of the commercial signs that we see in everyday life have their roots in the distant past. Not only do they project the brand-product relationship in people's minds, but they induce, in a much more profound way, a timeless and universal quality that only myths and archetypes can reveal. The Gauloises' helmet, on first level, recalls a type of cigarette, but on a second, deeper level, the winged helmet of Mercury (or

Left

Photograph 1

The Gauloises' helmet

Right

Photograph 2

Mr Proper
Hermes), ambassador of the Gods and mediator between Heaven and Earth, without forgetting the wing's symbolism of uplift, lightness and angel-like qualities.

The Mr Proper muscleman is an obvious symbol of what the product represents in the mind of the housewife, but it also hides a more important figure, the servant of Aladdin's lamp ('Tales of a thousand and one nights') - the one who can make all the lamp-owner's dreams and desires come true, if they know its secret. The relationship between the lamp and cleaning is interesting to think about ....

The universal symbol of the number seven is present in the Seven Up brand. Seven is the number of the Creation (Genesis) and of the Apocalypse (the Recreation of the world). Seven is the number of perfect totality and fullness, the number of a completed cycle. It is the number that is not completely human, and that is associated with all that is mysterious and celestial; most of the time it is the number of happiness and utmost integrity, as

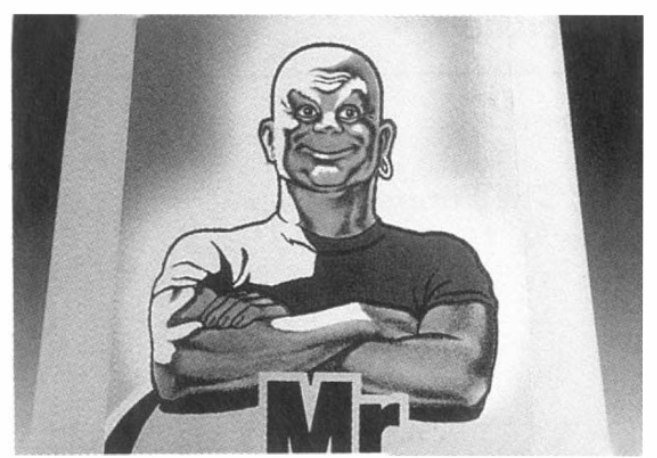


in seventh Heaven.

By referring to the religious - the Quaker - of the Quaker Oats brand, this symbol recalls the purity and simplicity adopted by this religious sect which originated in Britain. The founder of the Quakers, George Fox (1624-91) said to the judge at his trial: 'Tremble before the Wrath of God', to which the judge replied: 'You are only tremblers', that's to say quakers.

These few examples should also be analysed from the point of view of the symbolism of colour:

- Seven up is associated with red and green, the two colours of life, the colour of blood and solar energy, and the colour of sap and vegetation that is born, dies and is reborn with each cycle.

- Gauloises' blue is the Heavenly colour, the colour of nightime imagination, more feminine than masculine.

- Mr Proper is associated with yellow, the colour of action and light.

- The Quaker on the Quaker Oats package is portrayed in blue and white, the colours of mystic purity.

Each colour, like each number, shows a sign-symbol in a new light. One could even say that the colour (the Nivea dark blue, the Ovomaltine orange, Schweppes yellow, Milka mauve, Marlboro's red and white) completes the brand personality by juxtaposing the colour's symbolic signification or its number.

\section{THE PSYCHOANALYSIS OF A BRAND}

The last part of my book proposes a mnemotecnic system of brand analysis. This system consists of two different but complementary levels: the psychological level which I have defined using four basic criteria:
- the personality;

- its expression (conceptualisation);

and the physical consisting of four other criteria:

- the shape (form);

- the means used to promote the brand (applications);

- the rules for its use (usage);

- its distribution (brand communication).

When a brand has been around for a certain time, analysing the first level consists mainly of verifying that the brand's mission has not changed or, if it has, that its personality does not need to be adapted to a new marketing situation. The two other criteria: the name and the way the brand expresses itself are an integral part of the history and roots of the brand. Changing these criteria is the equivalent of replacing the brand by something totally new, and therefore, losing forever the brand's equity and content.

A brand name is effectively inalterable, and to change it is to change its individuality and turn it into something else. In all traditions a name is related to someone, and to have the rights to a name is the equivalent of owning the soul and the spirit of the person who carries it. Consequently in the case of a new brand it is necessary to give a

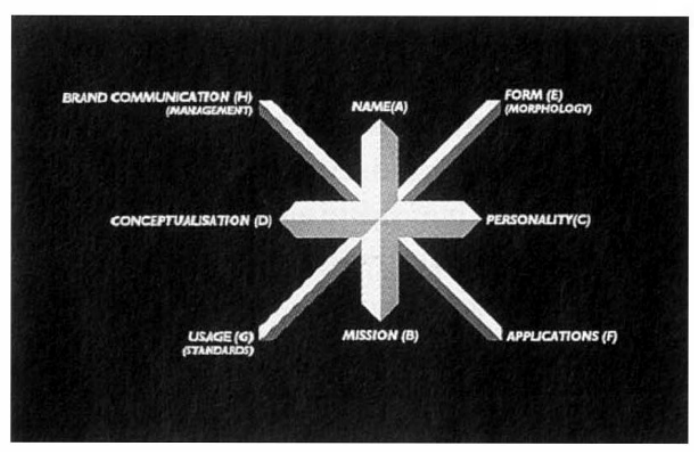

Photograph 3

The conceptual process of the brand

- the name;

- the mission; 


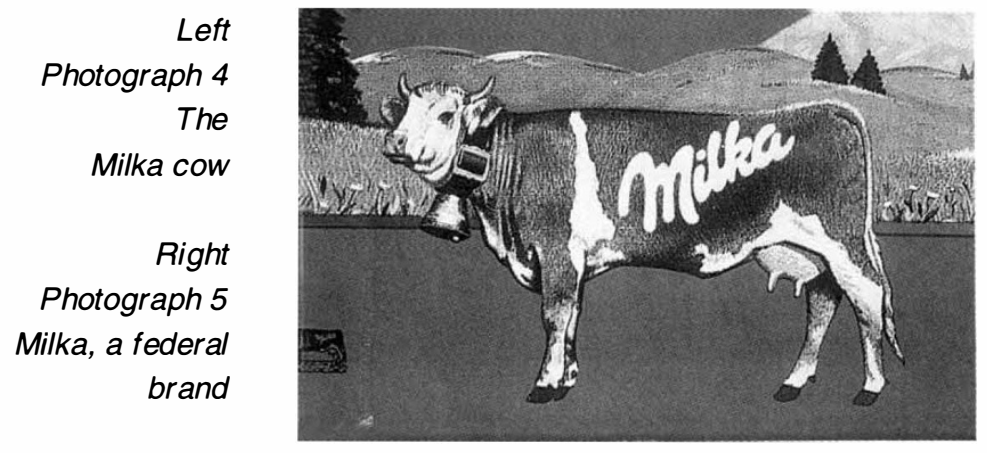

lot of thought to the name, and especially its international implications. Too many brands are univocal, having a meaning in only one language.

'The expression of something is the birth of a concept in the eyes of its creator.'2 This expression is the verbal translation of the brand personality. That is to say that if a new brand positioning is defined, it is absolutely necessary to change dramatically its visual identity. This was the case when we became involved in the rebirth of the Talbot brand. The name was part of automotive history, but its vocation had completely changed, leading us to redesign totally the sign-symbol while retaining the brand name. In 1979 Talbot became a new make of car as opposed to being the relaunch of an old brand.

The Bic brand was originally a single product brand. Nowadays it covers a range of products unrelated to writing. The brand's purpose has changed: from being associated uniquely with handwriting (ball-point pens) it is now associated with throw away products: the razor, cigarette lighter and ballpoint pen that are disposed with after use and have given the brand a completely different environment, even though it may not be completely homogenous. The brand failed to launch successfully a throw-away perfume as the concept of 'throw away' is in

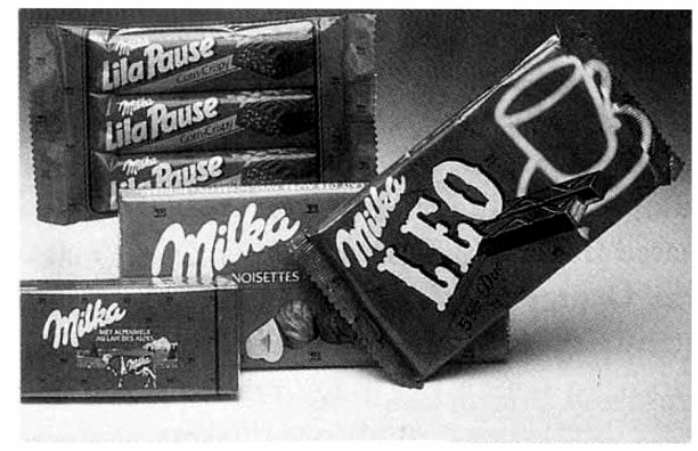

consumers' minds contradictory to the nature of perfume.

It is only the brand's personality that can define the combination of ideas, attitudes and attributes or qualities that the consumer associates with a brand. A brand's personality cannot fundamentally change, but it can enrich itself, enlarge or reduce its territory, go from being national to international, from single product to multiproduct; or it can become a federal brand like Milka. This began as a single, milk chocolate product. Today, its mauve banner covers a series of national brands that Kraft Jacobs Suchard-Côte d'Or has in different countries (Melo Cake, Lila Pause, Leo, etc).

Milka is still associated with chocolate, but its territory has grown.noticeably In this case, apart from the brand colour, it's the typestyle of the logo that symbolises that essential componant of Milka: milk. Milka is written in letters that express milk, purity, unctuousness, and the dietary richness of this beverage...

As an example we can take the personality of Knorr, a brand that was redesigned in 1987 and which was created in 1838 by C.H. Knorr.

Since then the brand has gained ground. It now covers thousands of food products in 46 countries, 22 of them in Europe. At the 


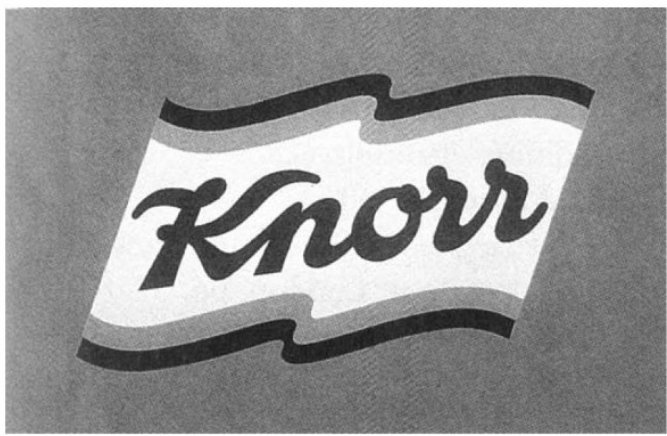

beginning, around 1870 , it was a monoproduct brand producing dehydrated soups in sachets. Today it is a world brand.

So here is the portrait of this talented grand master: 'Mr Knorr is intransigent about the quality of his products. He is popular, sympathetic and friendly. His knowhow and creativity are the basis of recipes that are original and top quality. He integrates modern technology into his work and is a recognised authority. His main professional objective is to produce exclusive products that people are delighted to taste either alone or in company.'3

For the mission statement as for the personality, it is necessary to verify on a regular basis that they are still accurate.

One could say that psychological aspects of a brand are the hidden aspects. They constitute the spirit of the sign - the physical aspect being the visible elements - the form and the colour; the support used; the rules to be respected; the distribution strategy and the concurrent control of all that is material to the brand and its visual expression. The form of a brand can be complex or simple. In the most simple versions, they are generally limited to the typestyle of the brand name (Kellogg's, Perrier, Caran d'Ache, Schweppes, Milka, Nivea, etc) either tied or not to a brand colour.
In the most complex cases that brand is not only the typestyle of the brand name, but a sign-symbol which can be elaborated, or not. The ensemble can be either in two dimensions (no relief), in volume or, in many cases, animated. That is to say that the brand is constructed by television, or cinema animation or the interplay of light of an illuminated sign. The form is therefore simultaneously writing (word), colour, sign, pictogram, ideogram, volume, movement, texture etc. It is the body of the brand and susceptible to change with time.

It is obvious that our current visual environment is not that of the 1930s and that very often the style of an era is reflected in the graphics of the period. At brand level, one can make it evolve, but at the same time ensuring that it retains its brand equity, that is its soul (see further reference).

A brand's supports are tied to its different levels of communication. The signature of an ad or poster, the brand on the package, in an annual report, or in association with a cultural event, are four different levels of communication, but all convey the same brand identity. In other words, a brand must be able to exist in different environments, while remaining true to itself.

Brand supports imply not only different levels of communication, but all the materials associated with its transmission (paper, carton, metal, plastics, fabrics etc) and its different forms of presentation (horizontal, vertical, in volume, opacity or light etc).

Certain of these applications are illustrated in the brand manual which explains the rules of how to use the brand image. A company can ensure the brand's recognition both inside and outside the company by using the appropriate media for its target group. A service company would not choose the same media as a consumer product group or a company producing industrial products.

It is the decision of the advertising or communications manager whether to use
Photograph 6 Knorr 
the brand horizontally or vertically - vertically, taking into account the different types of communication (internal, external, product and company etc), or horizontally in function of the usage areas and the different product versions. It is not an easy task in this age of territorial expansion, brand lineexpansion and company mergers. It is in this way that a company can co-ordinate 4 its efforts in terms of international advertising, packaging strategy and public relations and sponsoring.

\section{References}

(1) J. Behaeghel (1994) 'Voyage Symbolique dans la Marque', Vif Éditions, Brussels.

(2) ibid., pp. 215-30.

(3) J. Behaeghel (1991) 'Brand Packaging', Phaidon Press, London, pp. 37-8.

(4) ibid., p. 80. 